\title{
The Relationship between Personality Traits and Stress Levels in Children
}

\author{
Jéssica Elandra Bedin1, Mariane Luiza Mattjie², Vinícius Renato Thomé Ferreira², \\ Denice Bortolin Baseggio² \\ ${ }^{1}$ Psychology, Passo Fundo, Brazil \\ ${ }^{2}$ Department of Psychology, Faculda de Meridional, Passo Fundo, Brazil \\ Email: mariane.mattjie@imed.edu.br
}

Received 26 March 2015; accepted 28 April 2015; published 5 May 2015

Copyright (C) 2015 by authors and Scientific Research Publishing Inc.

This work is licensed under the Creative Commons Attribution International License (CC BY). http://creativecommons.org/licenses/by/4.0/

cC) (i) Open Access

\begin{abstract}
This study assessed the relationship between the personality traits and stress levels in children. The Scale of Children Personality Traits and the Scale of Infant Stress were administered. The personality trait dimensions refer to neuroticism, psychoticism, extroversion and sociability, and the stress dimensions refer to levels of stress resistance, alertness, near-exhaustion and exhaustion and the stress reaction types regarding the psychological, psychological with depressing component, psychophysiological and physic types. Fifty children of both genders were assessed; all of them studied in classes from the first to the fourth grades of an elementary public school. The data indicate moderate and positive correlations between the neuroticism and stress levels traits, being mainly evidenced in psychological reactions. On the other hand, the traits psychoticism, extroversion and sociability did not present significant correlations with the sample stress levels.
\end{abstract}

\section{Keywords}

Personality Trait, Stress, Psychological Assessment

\section{Introduction}

In the current scenario, consumerism, immediacy and cultural speed have been affecting significantly children's identity, obligating them to adapt to contextual pressures and to adopt to a posture, sometimes, inconsistent with their development stage. Children in the modern world are frequently responsible for having a well-developed intellect; they are increasingly more directed to take family roles and to involve in activities that go beyond school assignments, such as swimming classes, soccer practice, ballets and foreign languages. In order to adapt to the present scenario, children are required to have an emotional charge that they sometimes are not always 
ready to bear.

The term stress refers to a tension state that bursts the individual's internal homeostasis, developing physiological and psychic reactions, and forcing the organism to respond in some way. Such imbalance generates depletion, in a way that, in order to regain balance, it is necessary to use physical and mental energies reserves (Elkind, 2004; Lipp, 2000). Eisenstein, Jorge, \& Lima (2009) state that stress comprises conflicts, threats to integrity and deprivation of the individual's liberty and occurs when there are significant losses, such as the loss of the house, the loss of people who have any link with the individual or other conditions that affectively involve one's life. In this perspective, Lipp \& Lucarelli (2011) highlight that many can be the causes of stress, among them, the disagreement between the parents, death of relatives, changes either in the house or at school, and excess of activities, waiting for events and parents' divorce.

There are phases of stress in which a child can go through; these phases indicate and measure the seriousness and the stress presence degree in the child's life, which will depend not only on the stressing situation, but also on its intensity and the child's vulnerability (Bignotto, 2010). According to Lipp \& Lucarelli (2011), stress can be measured based on stages: alertness; resistance; near-exhaustion and exhaustion phase. For the authors, alertness phase concerns a type of passing stress, which requires a reaction from the organism, for it represents something challenging for the child. Resistance phase happens when the stressor is not eliminated, remaining active for a long time, and a high energy level to confront it is required from the child.

Regarding the near-exhaustion and exhaustion phases, they are the most serious stages, in a way that the child cannot deal with the stressors, there is a type of imbalance, depleting the organism significantly and the child gets sick in a physic and psychological manner.

Stress is perceived by means of symptomatology issued by the child, and the symptoms presented vary according to the child's singularity and to the stress phase perceived in the child. These stress reactions can be: psychological, physical, psychological with depressing component and psychophysiological (Lipp \& Lucarelli, 2011). Regarding the psychological symptoms, it is possible to highlight anxiety, night terror, nightmares, difficulties in relationships, urge to cry, sadness, sudden isolation, insecurity, fears, discouragement, apathy and aggressive acting. Inversely, when there is the predominance of physiological reactions to stress, the child starts presenting diarrhea, stomach ache, tics, nauseas, nocturnal enuresis, loss of or excessive appetite, stuttering, muscular pain, and headaches and the child starts to grit the teeth and can behave in a hyperactive manner (Lipp \& Lucarelli, 2011; Lipp, 2004).

Still, regarding stress reactions, Lipp (2004) indicates that the psychological reactions with depressive component are those in which the child starts losing the purpose of life, losing energy and the interest in executing their tasks. Still, self-image is perceived as negative, they become more forgetful, fights happen within the family environment and they stop investing on themselves. Concerning the psychophysiological issues, it is possible to perceive in the child hyperactive behavior, causing difficulty to pay attention to some stimulus, shyness, heart acceleration, difficulty in breathing and low immunity (Lipp, 2004; Lipp \& Lucarelli, 2011).

The way the child handles stress is peculiar, that depends on the way the child perceives the stressing situation, on the level of stress that he or she is facing and the mechanisms he or she presents to deal with it. In this way, the child is going through a developing process and events occurring in the daily life can be associated by the child in many ways, which leads to a peculiar manner of dealing with each situation. This diversified way of reacting to an event is linked to the predominance of the child's personality characteristics (Weber, 2011).

de Souza Martins \& Lopes (2010) describe personality as one of the most complex terms psychology seeks comprehending. Thus, it can be understood as a combination of feelings, thoughts and behavior, in other words, what is singular to every individual. Also regarding this aspect, Schestatsky (2012) perceives personality as the result of the interaction of biological, environmental and experimental factors of the subject, in other words, personality concerns how a person experiences events, reacts to others and to herself or himself, as well as, which individual's characteristics are durable and stable.

According to Sisto (2004a), the individual reorganizes itself as it encounters circumstances and experiences in life, but even though that happens, there are trends, or personality traits, that are perceptible and make the child different from others, thus, ensuring the uniqueness and differentiation of the child. Considering that personality is a dynamic process and it is marked by some predispositions, that is, the personality traits overcome the present-time behavior, but it is evidenced in what is repeated throughout the individual's life. When considering personality traits, it is soon referred to the individual's behavior, given that the traits are reflected in the subject, though what really characterizes the personality traits is the uniqueness of the child's behaviors which are evi- 
denced by its stability and consistency.

Regarding the Diagnostic and Statistical Manual of Mental Disorders DSM-5 (2014), personality traits can be understood as a persistent manner of perceiving, relating to and thinking about oneself and about others. In this way, this functioning manner of the individual will certainly externalize, becoming perceptible in the various contexts within which the individual is inserted. Likewise, Junior, Lima and Lopes (2014) state that personality traits make the individual react in its own way, that is, they allow the individual, after a stimulus, to interpret it according to its uniqueness and thus, emit a reaction. These reactions happen according to the psychic functioning of the individual, being expressed commonly by the behavior.

The peculiarity of each personality trait does not concern solely the behaviors emitted by the individual, but also takes into consideration the expression of emotions and the child's cognitive aspects. Thus, this approach proposes personality as something complex, comprising behavioral, cognitive and emotional issues, hence, it is possible to consider that some faults of the mentioned orders might be related to the personality traits (Bartholomeu, 2005).

Personality is assessed in many ways, wherein, some psychological tests propose an objective assessment of it, offering the classification and description of the following traits: psychoticism, neuroticism, extroversion and sociability. Each one of them refers to a particular and unique way for the child to relate with the environment, and naturally one of the traits will be more present and more striking in the child and another will be more absent and more attenuated, what makes the child unique when relating to the world around. Thus, when the description of personality traits occurs, literature discusses about the perspective of this trait being strongly present or the opposite, being weakly present in the subject's personality (Sisto, 2004b).

The extroversion trait can be understood as characteristic of people with skills of interpersonal relationships, optimism, impulsiveness and somewhat carefree. People with this trait's characteristics show preference for being accompanied and for activities that involve adventure, they like changing and they are participative. On the other hand, people with minor or low extroversion traits tend to be more timid and, regarding their actions, they are organized and controlling people, preferring activities with low social contact (Sisto, 2004a; Sisto \& Rueda, 2008).

Concerning the psychoticism trait, when its presence is strongly perceived as a personality trait, the child can have as characteristics the carelessness regarding others, feeling delight in disturbing them, at times, proving to be hostile and preferring solitary activities, showing little preoccupation with situations that involve danger (Sisto \& Rueda, 2008; Fernandes, Bartholomeu, Rueda, Suehiro, \& Sisto, 2005). On the other hand, children with no evidence of this trait tend to be more sensitive and concern about other people (Sisto, Bueno, \& Rueda, 2003).

According to Sisto, Bueno, \& Rueda (2003) regarding the neuroticism trait, children with this trait's characteristic tend to be more concerned, presenting anxiety symptoms, mood instability and consequently emotional instability, displaying distress with situations and factors that could go wrong, evidencing early anxiety to predict events, thus, they present anxiogenic reactions in face of new and unexpected situations. Yet, people without indicators of this trait can present a healthy self-control, being more focused on their activities and showing low impulsiveness.

In the sociability trait, children with high indices in it, tend to present facility in accepting the context and the socially imposed rules, as well as, behaving within what is expected, without any difficulties for that. Yet, people with no indication of this trait, show who they actually are, being characterized by their independence in face of the rules and, in some cases, they might need clinical care, due to the possibility of the presence of antisocial conducts (Sisto, 2004a; Sisto, Oliveira, de Oliveira, Bartholomeu, Oliveira, \& Costa, 2004).

Stress in children has been demonstrated to be present in the daily life, new situations have been constantly arising, demanding an action from the individual in face of the diversity of events, adjustments and situations of which they go through. The events are perceived by each child in a different way and, thus, their way of reacting in face of this range of situations becomes a lot peculiar once that, the stress levels experienced by each child vary according to their perceptions and experiences in face of the stressors. Di Pascuale, Rivas, Cabaña, \& Di Pascuale Casanela (2011) highlight that when the personality traits are very rigid and inflexible, they can begin to affect the individual and its social relations, bringing a series of physical and psychological manifestations that can compromise the health of the individual.

Based on these considerations, and being the personality mediated by biological, social and psychological aspects, some personality traits can be related to phases and forms of reactions to stress. That is, stress experienced 
by the child and the stress perceived in the psychological, physical, psychophysiological and psychological with a depressing component symptom might have a relation with the personality traits and the unique and peculiar way of relating with the environment. In this way, the objective of this study was to identify the personality traits, reactions and stress phases presented by children, as well as verifying possible correlations between stress in children and their personality traits.

\section{Materials and Method}

This is a cross-sectional and quantitative study. Fifty children participated in it, with ages between 8 and 10 years (average, 8.72, standard deviation 0.11 , confidence level of the average at 95\%,0.21), attending public schools. The inclusion criteria for the subjects that participated in the research, and which the selecting process occurred by convenience, was of literate children, attending elementary school in a public school in the interior of the state of Rio Grande do Sul, Brazil. The project was approved by the Research Ethics Committee (CAAE 32629714.8.0000.5319, Report 720.211).

For the data collection, two instruments were used: ETPC (Escala de Traço de PersonalidadeInfantil) Personality Traits Scale for Children (Sisto, 2004a) and ESI (Escala de Stress Infantil) the Children's Stress Scale(Lipp and Lucarelli, 2011). ETPC assesses the personality traits (neuroticism, psychoticism, extroversion and sociability) presented by children with ages between 5 and 10 years, and consists of a set of 30 questions with the answer possibility of "Yes" or "No". Each subject might present a high or low score in more than one personality trait. ESI assesses children stress in four dimensions (physical reactions, psychological reactions, psychological reactions with a depressing component and psychophysiological reaction), and was developed for children with ages from 6 to 14 years. It consists of 35 statements involving symptoms and the child must respond to the statement according to the intensity at which the symptom applies on him or her.

For the presentation and analysis of the data, descriptive and inferential statistics were used. Inferential statistics consisted of non-parametrical analysis tools, considering that the instruments offer nominal or ordinal data (Dancey \& Reidy, 2013). The probability value considered in this study for the differences to be significant was of $p \leq 0.05$.

\section{Results}

Table 1 indicates the participants' personality traits, as a result from the survey performed with ETPC, divided into: weak (performance classified as equal to or lower than the quartile $25 \%$ ), moderate (performance classified between the quartile $25 \%$ and $75 \%$ ) and strong (performance classified as equal to or higher than the quartile $75 \%)$. The extroversion trait presented predominance of the average trait (98\%); psychoticism trait was weak on $98 \%$ of the respondents; neuroticism trait was predominantly weak on $42 \%$ of the respondents, presenting, however, a balance; and the sociability trait presented predominance as a strong trait (74\%).

Table 2 indicates that stress in an alert level was perceived in $93.1 \%$ of the boys and in $71.4 \%$ of the girls that participated in the study. Stress in a resistance level is present in $3.4 \%$ of the male sample and in $14.3 \%$ of the female sample. The most serious level of stress found in the study was the near-exhaustion one, present in $3.4 \%$ of the boys and in $14.3 \%$ of the girls. The exhaustion stage, which represents the highest stage of stress was not perceived.

Table 3 presents the performance of the participants in the ETPC and in the ESI by gender. Statistically significant differences using Mann-Whitney test were not found in the extroversion, psychoticism and sociability

Table 1. Children personality traits, identified through ETPC.

\begin{tabular}{cccc}
\hline & Weak Trait & Moderate Trait & Strong Trait \\
\hline Extroversion Trait & $2 \%$ & $98 \%$ & $0 \%$ \\
Psychoticism Trait & $98 \%$ & $2 \%$ & $0 \%$ \\
Neuroticism Trait & $42 \%$ & $24 \%$ & $34 \%$ \\
Sociability Trait & $8 \%$ & $18 \%$ & $74 \%$ \\
\hline
\end{tabular}

Source: Primary. 
Table 2. Stress stages of the CSS by gender.

\begin{tabular}{cccccccc}
\hline & \multicolumn{2}{c}{ Male } & \multicolumn{2}{c}{ Female } & \multicolumn{2}{c}{ Total } \\
\cline { 2 - 7 } & $\mathrm{n}$ & $\%$ & $\mathrm{n}$ & $\%$ & $\mathrm{n}$ & $\%$ \\
\hline Alert Stage & 27 & 93.1 & 15 & 71.4 & 42 & 84.0 \\
Resistance Stage & 1 & 3.4 & 3 & 14.3 & 4 & 8.0 \\
Near-Exhaustion Stage & 1 & 3.4 & 3 & 14.3 & 4 & 8.0 \\
Total & 29 & 100.0 & 21 & 100.0 & 50 & 100.0 \\
\hline
\end{tabular}

Source: Primary.

Table 3. Performance of the participants in the PTSC and in the CSS.

\begin{tabular}{|c|c|c|c|c|c|c|c|c|c|c|c|c|c|}
\hline & & \multicolumn{3}{|c|}{ Female } & \multicolumn{3}{|c|}{ Male } & \multicolumn{3}{|c|}{ Total } & \multicolumn{3}{|c|}{ Mann-Whitney } \\
\hline & & Average & $\mathrm{SD}$ & $\begin{array}{l}\text { CLA } \\
95 \%\end{array}$ & Average & $\mathrm{SD}$ & $\begin{array}{l}\text { CLA } \\
95 \%\end{array}$ & Average & SD & $\begin{array}{l}\text { CLA } \\
95 \%\end{array}$ & d & $\mathrm{U}$ & Bicaudalp \\
\hline \multirow{4}{*}{ PTSC } & Extroversion & 6.62 & 0.97 & 0.21 & 6.72 & 1.79 & 0.33 & 6.68 & 1.49 & 0.21 & 0.04 & 263.5 & 0.42 \\
\hline & Psychoticism & 1.67 & 0.91 & 0.20 & 2.69 & 2.07 & 0.38 & 2.26 & 1.75 & 0.25 & 0.70 & 217.00 & 0.08 \\
\hline & Neuroticism & 3.95 & 2.11 & 0.46 & 3.34 & 2.41 & 0.45 & 3.60 & 2.29 & 0.32 & 0.29 & 260.00 & 0.38 \\
\hline & Sociability & 4.38 & 1.32 & 0.29 & 4.28 & 1.69 & 0.31 & 4.32 & 1.53 & 0.22 & 0.06 & 301.50 & 0.95 \\
\hline \multirow{5}{*}{ CSS } & Physical Reactions & 10.86 & 5.56 & 1.21 & 7.17 & 5.00 & 0.93 & 8.72 & 5.50 & 0.78 & 0.78 & 187.00 & 0.02 \\
\hline & $\begin{array}{l}\text { Psychological } \\
\text { Reactions }\end{array}$ & 18.62 & 9.04 & 1.97 & 9.66 & 6.40 & 1.19 & 13.42 & 8.76 & 1.24 & 1.32 & 122.00 & $<0.001$ \\
\hline & $\begin{array}{l}\text { Psychological Reactions } \\
\text { with Depressing Component }\end{array}$ & 9.19 & 5.38 & 1.17 & 6.69 & 6.19 & 1.15 & 7.74 & 5.94 & 0.84 & 0.51 & 213.50 & 0.07 \\
\hline & $\begin{array}{l}\text { Psychophysiological } \\
\text { Reactions }\end{array}$ & 10.05 & 5.59 & 1.22 & 7.66 & 5.65 & 1.05 & 8.66 & 5.70 & 0.81 & 0.48 & 212.00 & 0.07 \\
\hline & Total Stress & 49.19 & 22.92 & 5.00 & 31.17 & 20.91 & 3.88 & 38.74 & 23.35 & 3.30 & 0.90 & 170.50 & $<0.01$ \\
\hline
\end{tabular}

Values indicated by $(*)$ indicate $p \leq 0.05$. Values indicated by $(* *)$ represent values close to $p \leq 0.05$. Source: Primary.

traits. Stress levels, on the other hand, presented statistically significant differences between the groups in the dimensions of physical reactions $(\mathrm{U}=187, p=0.02)$, psychological reactions $(\mathrm{U}=122, p<0.001)$ and the instrument's total $(\mathrm{U}=170.5, p<0.01)$. Although psychological reactions with depressing component $(\mathrm{U}=213.5$, $p=0.07)$ and psychophysiological reactions $(\mathrm{U}=212, p=0.07)$ did not reach the level of $p \leq 0.05$, the values approached the stipulated a priori; in the same way, psychoticism trait presented $\mathrm{p}$ values close to $0.05(\mathrm{U}=217$, $p=0.08$ ).

Table 4 indicates few intratest correlations (Spearman's $\rho$ ) between the ETPC personality traits (all of them below $\rho=0.5$ ), but for a lot of intratest correlations of the ESI dimensions (all of them above $\rho=0.65$ ). Correlations with $\rho=0.6$ were considered strong (Dancey \& Reidy, 2013). These findings suggest that the personality traits are low correlated, whereas the stress components are highly correlated amongst themselves. The comparison between tests did not indicate any value of $\rho \geq 0.5$; nonetheless, there were correlations close to this value between the ETPC neuroticism trait and the ESI psychological reactions $(\rho=0.49, p \leq 0.01)$ and between neroticism and the stress total performance $(\rho=0.45, p \leq 0.01)$.

Table 5 presents the comparison between the personality traits and the types of reaction to stress indicated that the medium and high neuroticism trait presented the highest scores in all types of stress: physical reactions $\left(\mathrm{X}^{2}=\right.$ $8.75, p=0.01)$, psychological reactions $\left(\mathrm{X}^{2}=15.92, p<0.01\right)$, psychological reactions with depressing component $\left(\mathrm{X}^{2}=11.14, p<0.01\right)$ and psychophysiological reactions $\left(\mathrm{X}^{2}=13.94, p<0.01\right)$. The medium trait of sociability presented the scores of greater damage in the types of stress (physical reactions, $\mathrm{X}^{2}=6.03, p=0.05$; psychological 
Table 4. Correlations (Spearman's $\rho$ ) between the ETPC and the ESI.

\begin{tabular}{|c|c|c|c|c|c|c|c|c|c|}
\hline & Extroversion & Psychoticism & Neuroticism & Sociability & $\begin{array}{l}\text { Physical } \\
\text { Reactions }\end{array}$ & $\begin{array}{l}\text { Psychological } \\
\text { Reactions }\end{array}$ & $\begin{array}{l}\text { Psychological Reactions } \\
\text { with Depressing Component }\end{array}$ & $\begin{array}{c}\text { Psycho-Physiological } \\
\text { Reactions }\end{array}$ & Total \\
\hline Extroversion & $\begin{array}{c}1.00 \\
(-)\end{array}$ & & & & & & & & \\
\hline Psychoticism & $\begin{array}{c}0.29 \\
(0.04)\end{array}$ & $\begin{array}{c}1.00 \\
(-)\end{array}$ & & & & & & & \\
\hline Neuroticism & $\begin{array}{c}0.27 \\
(0.06)\end{array}$ & $\begin{array}{c}0.09 \\
(0.54)\end{array}$ & $\begin{array}{c}1.00 \\
(-)\end{array}$ & & & & & & \\
\hline Sociability & $\begin{array}{l}-0.36 \\
(0.01)\end{array}$ & $\begin{array}{l}-0.42 \\
(<0.01)\end{array}$ & $\begin{array}{l}-0.31 \\
(0.03)\end{array}$ & $\begin{array}{c}1.00 \\
(-)\end{array}$ & & & & & \\
\hline Physical Reactions & $\begin{array}{c}0.01 \\
(0.97)\end{array}$ & $\begin{array}{c}0.13 \\
(0.35)\end{array}$ & $\begin{array}{c}0.35 \\
(0.01)\end{array}$ & $\begin{array}{l}-0.17 \\
(0.23)\end{array}$ & $\begin{array}{c}1.00 \\
(-)\end{array}$ & & & & \\
\hline $\begin{array}{l}\text { Psychological } \\
\text { Reactions }\end{array}$ & $\begin{array}{l}-0.07 \\
(0.62)\end{array}$ & $\begin{array}{l}-0.09 \\
(0.55)\end{array}$ & $\begin{array}{c}0.49 \\
(<0.01)\end{array}$ & $\begin{array}{l}-0.22 \\
(0.13)\end{array}$ & $\begin{array}{c}0.76 \\
(<0.01)\end{array}$ & $\begin{array}{c}1.00 \\
(-)\end{array}$ & & & \\
\hline $\begin{array}{c}\text { Psychological } \\
\text { Reactions with } \\
\text { Depressing } \\
\text { Component }\end{array}$ & $\begin{array}{l}-0.02 \\
(0.87)\end{array}$ & $\begin{array}{c}0.27 \\
(0.05)\end{array}$ & $\begin{array}{c}0.38 \\
(0.01)\end{array}$ & $\begin{array}{l}-0.41 \\
(<0.01)\end{array}$ & $\begin{array}{c}0.75 \\
(<0.01)\end{array}$ & $\begin{array}{c}0.76 \\
(<0.01)\end{array}$ & $\begin{array}{c}1.00 \\
(-)\end{array}$ & & \\
\hline $\begin{array}{l}\text { Psychophysiological } \\
\text { Reactions }\end{array}$ & $\begin{array}{c}0.08 \\
(0.57)\end{array}$ & $\begin{array}{c}0.27 \\
(0.06)\end{array}$ & $\begin{array}{c}0.38 \\
(0.01)\end{array}$ & $\begin{array}{l}-0.23 \\
(0.10)\end{array}$ & $\begin{array}{c}0.67 \\
(<0.01)\end{array}$ & $\begin{array}{c}0.66 \\
(<0.01)\end{array}$ & $\begin{array}{c}0.71 \\
(<0.01)\end{array}$ & $\begin{array}{c}1.00 \\
(-)\end{array}$ & \\
\hline Total Stress & $\begin{array}{l}-0.03 \\
(0.83)\end{array}$ & $\begin{array}{c}0.12 \\
(0.42)\end{array}$ & $\begin{array}{c}0.45 \\
(<0.01)\end{array}$ & $\begin{array}{l}-0.27 \\
(0.06)\end{array}$ & $\begin{array}{c}0.87 \\
(<0.01)\end{array}$ & $\begin{array}{c}0.90 \\
(<0.01)\end{array}$ & $\begin{array}{c}0.90 \\
(<0.01)\end{array}$ & $\begin{array}{c}0.84 \\
(<0.01)\end{array}$ & $\begin{array}{c}1.00 \\
(-)\end{array}$ \\
\hline
\end{tabular}

In the parentheses, values calculated of $p \cdot p$ values (-), not calculated. Values of $\rho \geq 0.6$ are indicated by an asterisk. Source: Primary.

Table 5. Comparison between the rows of personality traits and the perceived stress.

\begin{tabular}{|c|c|c|c|c|c|c|c|c|c|c|c|c|c|c|c|c|}
\hline & & \multicolumn{3}{|c|}{ Physical Reactions } & \multicolumn{3}{|c|}{$\begin{array}{l}\text { Psychological } \\
\text { Reactions }\end{array}$} & \multicolumn{3}{|c|}{$\begin{array}{l}\text { Psychological Reactions with } \\
\text { Depressing Component }\end{array}$} & \multicolumn{3}{|c|}{$\begin{array}{l}\text { Psychophysiological } \\
\text { Reactions }\end{array}$} & \multicolumn{3}{|c|}{ Total } \\
\hline & & Average & SD & $\begin{array}{l}\text { CLA } \\
95 \%\end{array}$ & Average & $\mathrm{SD}$ & $\begin{array}{l}\text { CLA } \\
95 \%\end{array}$ & Average & SD & $\begin{array}{l}\text { CLA } \\
95 \%\end{array}$ & Average & $\mathrm{SD}$ & $\begin{array}{l}\text { CLA } \\
95 \%\end{array}$ & Average & SD & $\begin{array}{l}\text { CLA } \\
95 \%\end{array}$ \\
\hline & Low & - & - & - & - & - & - & - & - & - & - & - & - & - & - & - \\
\hline Extroversion & Medium & 8.00 & 6.78 & 2.77 & 13.00 & 8.65 & 3.53 & 9.17 & 5.12 & 2.09 & 7.17 & 5.12 & 2.09 & 37.33 & 22.69 & 9.26 \\
\hline $\begin{array}{l}\text { Mann-Whitney } \\
\text { (U) }\end{array}$ & & 123 & & & 128.5 & & & 105 & & & 110 & & & 126.5 & & \\
\hline \multirow[t]{2}{*}{ Bicaudal $p$} & & 0.85 & & & 0.99 & & & 0.46 & & & 0.56 & & & 0.94 & & \\
\hline & Low & 8.77 & 5.82 & 0.98 & 14.09 & 9.21 & 1.56 & 7.26 & 5.68 & 0.96 & 7.83 & 5.22 & 0.88 & 38.23 & 24.06 & 4.07 \\
\hline Psychoticism & Medium & 8.79 & 5.01 & 1.34 & 11.87 & 7.67 & 1.98 & 8.87 & 6.57 & 1.70 & 10.60 & 6.45 & 1.66 & 39.93 & 22.37 & 5.77 \\
\hline Mann-Whitney (U) & & 241.5 & & & 204.5 & & & 219 & & & 169 & & & 237.5 & & \\
\hline \multirow[t]{2}{*}{ Two-Sided $p$} & & 0.94 & & & 0.37 & & & 0.56 & & & 0.09 & & & 0.87 & & \\
\hline & Low & 5.70 & 4.82 & 1.08 & 7.6 & 5.62 & 1.26 & 4.65 & 4.94 & 1.11 & 5.55 & 4.87 & 1.09 & 23.50 & 18.41 & 4.12 \\
\hline \multirow[t]{2}{*}{ Neuroticism } & Medium & 11.06 & 5.88 & 1.47 & 16.75 & 8.39 & 2.10 & 10.50 & 6.69 & 1.67 & 11.56 & 6.39 & 1.60 & 49.88 & 23.09 & 5.77 \\
\hline & High & 10.36 & 4.07 & 1.09 & 17.93 & 8.62 & 2.30 & 9.00 & 4.45 & 1.19 & 9.79 & 3.72 & 1.00 & 47.79 & 18.60 & 4.97 \\
\hline \multirow[t]{3}{*}{ Kruskal-Wallis $\left(\mathrm{X}^{2}\right)$} & & 8.75 & & & 15.92 & & & 10.02 & & & 11.14 & & & 13.94 & & \\
\hline & & 0.01 & & & $<0.01$ & & & $<0.01$ & & & $<0.01$ & & & $<0.01$ & & \\
\hline & Low & 7.00 & 3.90 & 1.59 & 11.83 & 3.66 & 1.49 & 11.67 & 5.09 & 2.08 & 9.83 & 5.91 & 2.41 & 40.33 & 12.53 & 5.12 \\
\hline Sociability & Medium & 10.07 & 4.79 & 0.89 & 15.66 & 8.71 & 1.62 & 8.45 & 5.93 & 1.10 & 10.00 & 5.41 & 1.00 & 44.52 & 22.36 & 4.15 \\
\hline Kruskal-Wallis $\left(\mathrm{X}^{2}\right)$ & & 6.03 & & & 5.87 & & & 7.96 & & & 6.88 & & & 7.29 & & \\
\hline$p$ & & 0.05 & & & 0.05 & & & 0.02 & & & 0.03 & & & 0.03 & & \\
\hline
\end{tabular}


reactions, $\mathrm{X}^{2}=5.87, p=0.05$; psychological reactions with depressing component, $\mathrm{X}^{2}=7.96, p=0.02$; psychophysiological reactions, $\mathrm{X}^{2}=6.88, p=0.03$ and total stress, $\mathrm{X}^{2}=7.29, p=0.03$ ) regarding high and low traits. Only the average psychoticism row presented psychophysiological reactions close to the value of $p=0.05$ $(\mathrm{U}=169, p=0.09)$.

Finally, the analysis of the differences between the personality traits and the stress levels (alertness, resistance and near-exhaustion) only indicated a difference statistically significant among children with a medium trait of neuroticism, that presented more frequency on the stages of resistance and near-exhaustion $\left(\mathrm{X}^{2}=9.34, \mathrm{gl}=4, p\right.$ $=0.05$ ). The remaining analyzes did not present statistically significant difference at the level of $p \leq 0.05$.

\section{Discussion}

The data obtained with the students with ages between 8 and 10 years indicated that the personality traits perform, in general, in the normal range. In the comparison between the genders, there was not the predominance of any personality trait, though the psychoticism trait presented a value close to the stipulated $(p \leq 0.05)$, and the masculine sample presented more characteristics. Relations between age, gender and personality traits shown by the ETPC instrument indicated that there is a significant difference in the psychoticism level in five-year-old children, differentiating the results from the masculine and the feminine samples, although the same is not confirmed in children with ages of 8,9 and 10 years (Sisto, 2004b).

The stress scores presented by the sample are generally located in the row of low symptoms. In the comparison between genders, though, the feminine group presented higher scores in the ESI in all the dimensions, with statistically significant differences in physical reactions, psychological reactions and in the ESI total performance. Stress vulnerability can be largely related to the difficulties in dealing with conflict situations and with the unexpected (Assunção \& Castro, 2011). In this way, the stress level and the stressor are felt differently by each individual, and the gender variables may contribute to these differences (Lupien, McEwen, Gunnar, \& Heim, 2009). The greater presence of stress symptoms in girls has been identified, when compared to boys (Lipp, Arantes, Buritti, \& Witzig, 2002), with higher scores in psychological reactions (Mombelli et al., 2011). Culturally the roles attributed to boys refer to maintaining emotional control and it is not allowed, as frequently as for girls, to externalize emotions and feelings. On the other hand, girls are more concerned with their performance and with attending the expectations of the family and the society, which can influence the intensification of the neuroticism trait and a higher stress level.

This study indicated, in a general way, few correlations of the ETPC personality traits amongst themselves, suggesting a clear difference between the test factors, which are independent (The manual does not present intra-factors studies.). ETPC points to behavioral aspects of the subject, however, Pacheco \& Sisto (2003) state that the traits are not unalterable, but they can be understood as tendencies that undergo continual changes. Though changes exist, there is certain consistency in the acting of each individual, thus the presence of personality traits is noticeable.

Regarding stress, considering the various strong correlations found, data suggest that damages (or high sores) in one of the dimensions is a predictor of a similar performance in the other dimensions. The major part of the sample, both masculine and feminine is in the minimum stage of stress. Alertness stage can be described as the one in which stress is transitory, but it presents a challenge to the child (Lipp \& Lucarelli, 2011). The child can react to stress in different ways, that is, children with a good capacity of reacting to stress, adverse situations are perceived as challenging, to which the child can adapt and overcome that context, without emitting emotional responses in a more serious way (Elkind, 2004; de Oliveira \& Lipp, 2009). Concerning the resistance stage, 3.4\% of the boys and $14.3 \%$ of the girls presented stress in this level. This stage requires a higher energy expenditure of the child, evidencing not only physical exhaustion, but also the child starts presenting memory impairment (Bignotto, 2010). Regarding the near-exhaustion stage, it could be perceived that $3.4 \%$ of the male sample and $14.3 \%$ of the female sample presented stress level in this stage. Children with stress level in this stage reached a higher score, they may then have the predominance of physical or psychological diseases, due to not being able to resist to the stressor (Lipp \& Lucarelli, 2011). The exhaustion stage, considered the most serious stage of stress, was not perceived in the children assessed, suggesting the non-occurrence of pathological stress levels.

Data indicated moderate to strong correlations $(\rho \geq 0.6)$ between the ESI stress categories; nonetheless, the same was not perceived between the ETPC personality traits, which presented weak and even negative correlations $(\rho<0.3)$. Stress is characterized as a set of reactions, in this way, studies of Lipp \& Lucarelli (2011) indi- 
cated high correlation between stress reactions, showing thus that the ESI instrument measures an element in common. Yet, concerning personality, studies performed by Sisto (2004a) describe that the four scales are independent, being neuroticism, extroversion, sociability and psychoticism, in the studies of instrument's validity, related to the situations of teaching-learning and to other psychological and emotional situations.

In the correlation between instruments, only a moderate one was perceived between the personality trait of neuroticism and the psychological reactions to stress. Such relation is comprehensible, once that neuroticism is a factor associated to a higher psychological vulnerability, and the more the neuroticism trait is present, the more physical, psychological, psychological with depressing component and psychophysiological stress reactions can be evidenced. The findings of Ebstrup, Eplov, Pisinger, \& Jorgensen (2011) corroborate with these data, their findings evidenced that children with neuroticism trait presented susceptibility to stress. In this way, da S. Nunes, Hutz, \& Nunes (2010) indicate that subjects with neuroticism traits tend to express their emotions more intensely and present low tolerance to frustration. Correlational studies with neuroticism performed by Sisto, Bueno, \& Rueda (2003) indicate that such trait is associated with difficulties in calming down and with exaggerate emotional reactions to stimulus, still in this context, Sisto (2004b) aimed identifying associations between personality traits and emotions, in the results it was evidenced that neuroticism is correlated with fear and sadness, and there is a positive and significant correlation between these factors, and a negative correlation between neuroticism and courage, given that with the growth of neuroticism there was a reduction in courage.

\section{Conclusion}

Regarding personality traits, the most prevalent ones were the Sociability Trait and the Neuroticism Trait. In the comparison between the genders, the lack of predominance was perceived; nevertheless, the psychoticism trait almost reached the level statistical significance in the sense of the most symptoms in the male sample.

It was possible to assess the low general prevalence of stress. However, the female sample presented a higher frequency of stress symptoms of all types (physical reactions, psychological reactions, psychological reactions with depressing component and psychophysiological reactions), in addition to total stress. Such data are relevant, and indicate a possible difference in the way boys and girls manage and/or express stress behaviors. Future studies that manage to compare such differences are necessary, and the clinician must pay attention to this phenomenon.

In the comparison of the instruments, few strong correlations among ETPC traits occurred, whereas ESI presented several strong correlations among stress types. These findings indicate that the personality structure is defined in distinct dimensions, while the types of stress are closely related. However, in the correlation among instruments, only a moderate one was perceived between the personality trait of neuroticism and the psychological reactions to stress.

The study presented as the main limitation the size of the sample. Even using non-parametrical analysis tools (Dancey \& Reidy, 2013), a small sample number can significantly limit the capability of generalization of results (for example, it is possible to assess low extroversion traits and high psychoticism traits). Bigger samples, able to cover subjects with these traits, will enable a more precise understanding of the relations amomg these traits and the way stress is related.

Personality and stress are relevant themes for psychology and for mental health. The amplification of the number of studies relating personality aspects and other psychological phenomena (such as stress) is fundamental to help clinicians in the identification of associations among psychological phenomena. Thus, the capability of comprehending human development can be broadened and intervention strategies can be improved, which comes as a direct benefit to the patient and his or her family.

\section{Authors' Contributions}

J. E. B. and M. L. M. designed the experiment; J. E. B. performed the data collection; V. R. T. F., M. L. M. and J. E. B. analyzed the data; M. L. M. wrote to the journal. All the authors discussed the results. The authors declare that there is no financial interest herein. Correspondence and material request must be addressed to M. L. M. (mariane.mattjie@imed.edu.br).

\section{References}

Assunção, R. M., \& Castro, P. F. (2011). Relação entre estresse laboral e personalidade entre profissionais da área da saúde. 
Revista Saúde, 5, 4-16.

Bartholomeu, D. (2005). Traços de Personalidade e características emocionais de Crianças. Avaliação Psicológica, 4, 83-85.

Bignotto, M. M. (2010). A Eficácia do Treino de Controle do Stress Infantil. São Paulo: Tese de Doutorado, Pontifícia Universidade Católica de Campinas.

da S.Nunes, C. H. S., Hutz, C. S., \& Nunes, M. F. O. (2010). Bateria Fatorial da Personalidade: Manual técnico (1 ed., pp. 15-21). São Paulo: Casa do Psicólogo.

Dancey, C. P., \& Reidy, J. R. (2013). Estatística sem matemática para a psicologia (5th ed.). Porto Alegre: Artmed.

de Oliveira, J. B., \& Lipp, M. E. N. (2009). Resiliência e controle do stress em juízes e servidores públicos. Boletim Academia Paulista de Psicologia, 29, 287-306.

de Souza Martins, P. F., \& Lopes, E. J. (2010). Relação entre Personalidade, Transtornos de Ansiedade e de Humor: Uma Revisão de Literatura Brasileira. Revista Brasileira de Terapias Cognitivas, 6, 85-107.

Di Pascuale, L. B. B., Rivas, H. G., Cabaña, J. M. G., \& Di Pascuale Casalena, S. (2011). Los rasgos de personalidad y su relación con las enfermedades ulceropépticas. Salus, 15, 60-70.

DSM-5 (2014). Manual Diagnóstico e Estatístico de Transtornos Mentais. Nascimento, M. I. C. et al. Trad. (5th ed., pp. 646648). Porto Alegre: Artmed.

Ebstrup, J. F., Eplov, L. F., Pisinger, C., \& Jorgensen, T. (2011). Association between the Five Factor Personality Traits and Perceived Stress: Is the Effect Mediated by General Self-Efficacy? Anxiety, Stress \& Coping: An International Journal, 24, 407-419. http://dx.doi.org/10.1080/10615806.2010.540012

Eisenstein, E., Jorge, E., \& Lima, L. A. (2009). Transtorno do estresse pós-traumático e suas repercussões clínicas durante a adolescência. Revista Adolescência e Saúde, 6, 7-15.

Elkind, D. (2004). Sem tempo para ser criança: A infância estressada (3rd ed., pp. 146-240). Porto Alegre: Artmed.

Fernandes, D. C., Bartholomeu, D., Rueda, F. J. M., Suehiro, A. C. B., \& Sisto, F. F. (2005). Auto Concepto y Rasgos de Personalidad: Um EstudioCorrelacional. Psicologia Escolar e Educacional, 9, 15-25.

Lipp, M. E. N. (2000). O que eu tenho é stress? De onde ele vem? In M. E. N. Lipp (org.), O stress está dentro de você (2nd ed., pp. 11-18). São Paulo: Contexto.

Lipp, M. E. N. (2004). O stress da criança e suas consequências. In M. E. N. Lipp (Org.), Crianças Estressadas: Causas, Sintomas e Soluções (4th ed., pp. 18-36). Campinas: Papirus.

Lipp, M. E. N., \& Lucarelli, M. D. M. (2011). CSS: Escala de Stress Infantil: Manual. São Paulo: Casa do Psicólogo.

Lipp, M. E. N., Arantes, J. P., Buriti, M. do S., \& Witzig, T. (2002). O estresse em escolares. Psicologia Escolar e Educacional, 6, 51-56.

Lupien, S. J., McEwen, B. S., Gunnar, M. R., \& Heim, C. (2009). Effects of Stress throughout the Lifespan on the Brain, Behaviour and Cognition. Nature Reviews Neuroscience, 10, 434-445. http://dx.doi.org/10.1038/nrn2639

Mombelli, M. A., da Costa, J. B., Marcon, S. S., \& de Moura, C. B. (2011). Estrutura e suporte familiar como fatores de risco de stress infantil. Revista Estudos de Psicologia, 28, 327-335.

Pacheco, L., \& Sisto, F. F. (2003). Aprendizagem por interação e traços de personalidade. Psicologia Escolar e Educacional, 7, 69-76. http://dx.doi.org/10.1590/S1413-85572003000100007

Schestatsky, S. S. (2012). Desenvolvimento e Estruturação da Personalidade. In M. A. A. Brasil, E. P. Campos, G. F. do Amaral, \& J. G. M. de Medeiros (Orgs.), Psicologia Médica: A Dimensão Psicossocial da Prática Médica (pp. 26-30). Rio de Janeiro: Guanabara Koogan.

Sisto, F. F. (2004a). Escala de Traços de Personalidade para Crianças: Manual. São Paulo: Vetor.

Sisto, F. F. (2004b). Traços de Personalidade de Crianças e Emoções: Evidência de Validade. Paidéia, 14, $359-369$. http://dx.doi.org/10.1590/S0103-863X2004000300011

Sisto, F. F., \& Rueda, F. J. M. (2008). Estudo sobre as relações entre Autocontrole e Traços de Personalidade. Revista Semestral da Associação Brasileira de Psicologia Escolar e Educacional, 12, 369-380. http://dx.doi.org/10.1590/S1413-85572008000200008

Sisto, F. F., Bueno, J. M. H., \& Rueda, F. J. M. (2003). Traços de Personalidade na Infância e Distorção e Integração de Formas: Um Estudo de Validade. Psicologia em Estudo, 8, 77-84. http://dx.doi.org/10.1590/S1413-73722003000100010

Sisto, F. F., Oliveira, S. M. S. S., de Oliveira, K. L., Bartholomeu, D., Oliveira, J. C. S., \& Costa, O. R. S. (2004). Escala de traços de personalidade para crianças e aceitação social entre pares. Interação em Psicologia, 8, 15-24.

Weber, A. J. (2011). Características de Personalidade de Crianças Vítimas de Violência Doméstica. Santa Cruz do Sul: Universidade de Santa Cruz do Sul. 